\title{
The Rationality of (a Form of) Relative Identity
}

UWE MEIXNER

University of Regensburg

For anyone interested in metaphysical matters, there is much food for thought in David Wiggins's Sameness and Substance Renewed. I would like to ventilate some of the thoughts that have struck me when reading the book-thoughts that concern one of the metaphysically central issues raised by it: the issue of relative identity.

That relative identity does not-in fact, cannot-exist is one of Wiggins's main messages (see ibid., ch. 1). Consider, in particular, sortally relative identity. If (1) sortal identity (or identity under a sortal) is defined in the following way:

(DEF) $x$ is the same $f$ as $y={ }_{\text {Def }} x$ is an $f$, and $y$ is an $f$, and $x=y$ ("f," "g," etc. being variables for monadic sortal concepts, "sortal" being taken in a wide sense),

and if (2) Leibniz's Law is taken for granted, then sortally relative identity is impossible. For suppose we had an instance of sortally relative identity: $x$ is the same $f$ as $y$, but, although $x$ is a $g, x$ is not the same $g$ as $y$. Using the above definition, one immediately discovers that this supposition contradicts Leibniz's Law.

David Wiggins does not formally propose (DEF), but it seems to me that the notion of sortal identity he has in mind is exactly the one that is defined by (DEF). Given the acceptance of (DEF) and of Leibniz's Law, the negative conclusions Wiggins reaches against sortally relative identity are perfectly correct (though hardly surprising). I, for my part, do not believe that there is any better definition of sortal identity than (DEF), nor do I wish to tamper with Leibniz's Law. My misgivings are of a different sort.

Some champions of relative identity, I believe, could declare with considerable justification that Wiggins's arguments are irrelevant to their position, or, at any rate, irrelevant to what they had always wanted to assert but never quite managed to express properly. Let me illustrate. 
On p. 37 of Sameness and Substance Renewed, in the third line from the top, one encounters: " $\alpha$ ". On the same page, in the fifth line from the top, one encounters: " $\alpha$ ". Plato-putting the tip of his index finger first to the relevant spot in the third line and then to the relevant spot in the fifth line-declares: "This is the same letter as that." William-doing with his index finger what Plato did with his-declares the opposite: "This is not the same letter as that." John-a naive relativist regarding identity-offers what he believes is the perfect solution to this dispute. Using his index finger thrice in the way Plato and William used theirs, he says: "In a way, you are both right. For this is the same letter-type as that, but this is not the same letter-token as that. This and that are different letter-tokens." David, having observed the declaration of Plato's thesis, of William's antithesis, and of John's synthesis, is not content with this Hegelian procedure. He comments (using his index finger in the same way as the others used theirs): "If this is the same letter-type as that, as John proposes, then surely this is identical with that. Hence, if this-besides being a letter-type-is a letter-token and that-besides being a letter-type-is also a letter-token, as John's statement implies, then this and that are not only the same letter-type, but must surely also be the same letter-token-contrary to what John asserts. John's statement is simply self-contradictory." Yet Plato, William, John, and perhaps even David, feel that John's logically false statement aims at something that is quite correct. The problem is how to express it correctly.

Arnold - a sophisticated relativist regarding identity-has been silent so far. But now he speaks up (using his index finger in the same way as the others used theirs): "If this and that are letter-types, then this is the same letter-type as that. If, however, this and that are letter-tokens, then this is not the same letter-token as that. Or to make a somewhat stronger assertion: considered as letter-types, this is identical with that; but considered as letter-tokens, this is not identical with that. My point is that this and that can both be legitimately considered as letter-types, and can just as legitimately be both considered as letter-tokens. Their identity or non-identity is relative to the way in which they are ontologically interpreted. Plato, applying the word 'letter' to this and that, means by that word what is meant by the word 'letter-type.' He legitimately considers this and that as letter-types, and in consequence he is right when he asserts that this is the same letter (i.e., letter-type) as that. William, also applying the word 'letter' to this and that, means by that word what is meant by the word 'letter-token.' $\mathrm{He}$ legitimately considers this and that as letter-tokens, and in consequence he, too, is right when he asserts that this is not the same letter (i.e., letter-token) as that. Both are right, though it seems that they contradict each other."

"That's what I wanted to say," says John happily. But David is not yet satisfied. He queries: "How can this be legitimately considered to be a letter- 
type and be also legitimately considered to be a letter-token, when it is plainly impossible that this is both a letter-type and a letter-token?" And William growls: "There are no letter-types, I say." But Arnold gives the following answer: "My assertion that this can be legitimately considered to be a letter-type and can also be legitimately considered to be a letter-token covers the following two cases: (a) person One considers this at time $t_{1}$ to be a letter-type, and at time $t_{2}$ considers this to be a letter-token; (b) person One considers this at time $\mathrm{t}_{1}$ to be a letter-type, and person Two considers this at time $t_{1}$ to be a letter token (that, by the way, is the case of Plato and William). But my legitimacy-assertion does of course not also cover the following case: (c) person One considers this at time $\mathrm{t}_{1}$ to be a letter-type and a letter-token. Allow me to remark that we should not deny-not without very good reasons-the legitimacy of what is common practice among us. Perhaps there are no letter-types, but we certainly speak as if there are such entities. And we very easily move from considering this as a letter-token to considering this as a letter-type, and back again."

David does not give in: "If Plato points at this, and William, at the same time, also points at this, then, plainly, they are pointing at one entity, and not at two entities. So how can they both be right if William says implicitly that he is pointing at a letter-token, and Plato says implicitly that he is pointing at a letter-type, it being impossible that this is at the same time both a letter-type and a letter-token?" And Arnold answers: "I am not denying that William and Plato are pointing at one entity. But William considers that entity to be a letter-token, while Plato considers it to be a letter-type. They are interpreting the one entity they are pointing at in two ways-ways, I readily admit, which cannot be reasonably applied by one and the same person at one and the same time to one and the same entity. But there are no rationally obligating intersubjective grounds-nominalistic prejudice does not count—on the basis of which one would be able to decide whether Plato's interpretation of this is correct, or William's interpretation of this is correct. In this sense, they are both right if William says implicitly that he is pointing at a letter-token (which is different from that) and Plato says implicitly that he is pointing at a letter-type (which is the same as that)."

Should we not allow that Arnold-the sophisticated relativist regarding identity-has something going for his position? I believe so. It might be objected that the above example of defensible relative identity is irrelevant as far as discussing Sameness and Substance Renewed is concerned, since the example crucially involves universals (namely, letter-types) and is not solely concerned with three-dimensional continuants, which stand in the focus of Wiggins's book. But three-dimensional continuants are not utterly unlike universals. Though three-dimensional continuants, unlike universals, cannot accomplish the feat of being wholly present at different places at the same 
time, they, like universals, can be wholly present at the same place, or at different places, at different times. Here is an example of identity relative to sortal interpretation-initially misunderstood, as is usual, as sortally relative identity-that involves three-dimensional continuants only:

Aristotle, pointing at the floating object before him, asserts: "This is the same ship as the ship that Theseus sailed on many years ago." Thomas, pointing first at the floating object Aristotle pointed at and then at an object propped up in a hall nearby, asserts: "This is not the same ship as the ship that Theseus sailed on many years ago. The ship that Theseus sailed on many years ago is that."

What would John-if still a naive relativist regarding identity-have to offer in reaction to this disagreement? This: "In a way you are both right. For this [he is pointing at the floating object]-in view of unbroken continuity of function-is the same ship-instrument as the one that Theseus sailed on many years ago. But this [pointing at the floating object], in view of the replacement of each and every original part, is certainly a different ship-bulk than the one Theseus sailed on. That, however the is pointing at the object propped up in the hall], is indeed the same ship-bulk as the one that Theseus sailed on many years ago. Our antiquarians have carefully collected and reassembled the original parts."

We can count on it that David would not be happy about this analysis. This is what he would answer to John: "If, as you assert, this [pointing at the floating object] is the same ship-instrument as the one Theseus sailed on, then this and the ship-instrument that Theseus sailed on are identical. And if, as you also assert, that [pointing at the object in the hall] is the same shipbulk as the one that Theseus sailed on, then that and the ship-bulk that Theseus sailed on are identical. Hence there are two objects that Theseus sailed on, namely, this [pointing at the floating object] and that [pointing at the object in the hall]. But, as we all know, Theseus sailed only on one object, usually called 'Theseus' Ship'."

But Arnold-the sophisticated relativist regarding identity-would be able to put the matter better than John did, like this: "If the object Theseus sailed on and this [pointing at the floating object] are considered as ship-instruments, then this and the object Theseus sailed on are identical. But if the object that Theseus sailed on and this [the floating object] are considered as ship-bulks, then this and the object that Theseus sailed on are not identical. If, on the other hand, the object that Theseus sailed on and that [pointing at the object in the hall] are considered as ship-bulks, then that and the object that Theseus sailed on are identical. And let me add: if the object that Theseus sailed on and that [the object in the hall] are considered as ship-instruments, then that and the object that Theseus sailed on are not identical, for that has long been out of use, while the object that Theseus sailed on has not." 
Anticipating David's objections, Arnold would continue: "Let me emphasize that there is no doubt in my mind that there is only one object Theseus sailed on, only one object floating here before us, and only one object over there in the hall. But each of these objects can be sortally interpreted in two ways: as ship-instrument or as ship-bulk."

Perhaps David would wonder, with skeptical intent, how one and the same object could be sortally interpretable in such different ways. This is what Arnold would say in response: "Remember, first, the case of Plato and William. They agree that the objects they are talking about are letters. But they each interpret the word 'letter' in different ways. This is how it comes about that they also interpret the objects they both call 'letters' in different ways, which, in the end, leads to apparently contradictory identity-statements. Consider now the case of Aristotle and Thomas. They agree that the objects they are talking about are ships. But they each interpret the word 'ship' in different ways. This is how it comes about that they also interpret the objects they both call 'ships' in different ways, which, in the end, leads to apparently contradictory identity-statements." (Wiggins, in his own discussion of the Ship of Theseus in Sameness and Substance Renewed, touches on this idea, but rejects it as misplaced philosophical quietism; see ibid., pp. 94-5.)

According to Arnold, what is going on in the case of Plato and William, and in the case of Aristotle and Thomas, can be generally and abstractly described as follows:

There are objects $a_{1}, \ldots, a_{n}$ everybody, including person $A$ and person $B$, calls "F." But person A associates a different sortal concept with "F" than person $B$ does. The sortal concept person A associates with " $F$ " is $f_{A}$, and the different sortal concept person $B$ associates with " $F$ " is $f_{B}$. It may be conceptually possible or, on the contrary, conceptually impossible that any one of the objects $a_{1}, \ldots, a_{n}$ falls both under $f_{A}$ and under $f_{B}$. In any case, $f_{A}$ and $f_{B}$ are such that we do not have any rationally obligating intersubjective reason to apply $f_{A}$ rather than $f_{B}$, or $f_{B}$ rather than $f_{A}$, to any object out of $a_{1}, \ldots, a_{n}$. However, there is also no rationally obligating intersubjective reason against holding - but some plausible reason for holding - that every object out of $a_{1}$, $\ldots, a_{n}$ falls under $f_{A}$; and there is likewise no rationally obligating intersubjective reason against holding-but some plausible reason for holding-that every object out of $a_{1}, \ldots, a_{n}$ falls under $f_{B}$. Crucially, there are objects $a_{j}$ and $a_{k}$ out of $a_{1}, \ldots, a_{n}$ such that $a_{j}=a_{k}$ if both $a_{j}$ and $a_{k}$ fall under $f_{A}$, and such that $a_{j} \neq a_{k}$ if both $a_{j}$ and $a_{k}$ fall under $f_{B}$. Sooner or later this constellation will not fail to be mirrored in the identity-judgments made by the persons $A$ and $B$ regarding $a_{1}, \ldots, a_{n}$. Person $A$, by subsuming $a_{j}$ and $a_{k}$ under " $F$," subsumes $a_{j}$ and $a_{k}$ under $f_{A}$, and hence (quite reasonably) asserts: $a_{j}$ is the same $F$ as $\mathrm{a}_{\mathrm{k}}$. Person $\mathrm{B}$, by subsuming $\mathrm{a}_{\mathrm{j}}$ and $\mathrm{a}_{\mathrm{k}}$ under " $\mathrm{F}$," subsumes $\mathrm{a}_{\mathrm{j}}$ and $\mathrm{a}_{\mathrm{k}}$ under $\mathrm{f}_{B}$, and hence (just as reasonably) asserts: $\mathrm{a}_{j}$ is a different $\mathrm{F}$ than $\mathrm{a}_{\mathrm{k}}$. It is a 
move towards a reasonable resolution of the conflict between $A$ and $B$ to say, as a naïve relativist regarding identity would say, that " $a_{j}$ and $a_{k}$ are the same $F_{A}$, but different $F_{B} s$ " (where " $F_{A}$ " expresses $f_{A}$, and " $F_{B}$ " $f_{B}$ ). But this is not quite the correct way to phrase the statement of conflict-resolution. The correct way, which a sophisticated relativist regarding identity would use, is this: " $a_{j}$ and $a_{k}$, considered as $F_{A} s$, are identical, but considered as $F_{B} s$ they are different." (Nota bene: if $\mathrm{a}_{\mathrm{j}}$ and $\mathrm{a}_{\mathrm{k}}$, considered as $\mathrm{F}_{\mathrm{A}} \mathrm{s}$, are identical and are moreover, considered as $\mathrm{F}_{A} \mathrm{~s}$, both $\mathrm{F}_{B}$, then we will have: $\mathrm{a}_{\mathrm{j}}$ and $\mathrm{a}_{\mathrm{k}}$, considered as $\mathrm{F}_{\mathrm{A}} \mathrm{s}$, are the same $\mathrm{F}_{\mathrm{B}}$. But from this one cannot logically infer any one of the following three propositions: (a) that $a_{j}$ and $a_{k}$ are the same $F_{B}$, (b) that $a_{j}$ and $a_{k}$ are identical, (c) that $a_{j}$ and $a_{k}$, considered as $F_{B} s$, are identical.)

In view of these considerations, should we not allow that reasonable sense can be made of relative identity? Sortally relative identity is indeed indefensible, since " $x$ is the same $F$ as $y$ " logically implies " $x$ is identical with $y . "$ But its relative: identity relative to sortal interpretation-where " $\mathrm{x}$ and $\mathrm{y}$, considered (interpreted) as Fs, are identical" does not logically imply " $\mathrm{x}$ is identical with y"-certainly seems to occupy a useful place in our conceptual scheme as long as certain objects do not determine all by themselves their sortal interpretation and hence their identity-conditions. And who would dare to assert that the world tells us without any room for variation how we should sortally interpret all the objects in it? But if there is room for variation in our sortal interpretation of objects, then we may expect that at least in some cases identity is relative to sortal interpretation.

As another illustration of the usefulness of identity relative to sortal interpretation, consider that the concept makes possible a solution of a famous problem (due to Peter Geach), which is also taken up by David Wiggins (see Sameness and Substance Renewed, pp. 173-6). If Tibbles sits on the mat and has at least 1000 hairs, is there only one cat on the mat or are there at least 1001 cats on the mat? On the one hand, common sense dictates that there is only one cat on the mat: Tibbles. On the other hand, it seems arbitrary to deny cathood to any proper part of Tibbles which is such that it is Tibbles minus one of its hairs. But then it seems that there are at least 1001 cats on the mat-which is plainly absurd.

David Wiggins's solution of this problem consists in pointing out that there are no cats on the mat that lack a hair (ibid., p. 175). So there is only Tibbles on the mat after all.

True: there are no cats on the mat that lack a hair. But the proper parts of Tibbles that are Tibbles minus one of its hairs are not cats that lack a hair-at least not in the sense in which it is uncontroversially true to say that there are no cats on the mat that lack a hair. Just as Tibbles has all its hairs, so each of the mentioned proper parts of Tibbles has all its hairs, which are, in each case, Tibbles' hairs minus one of its hairs. Thus, although there is no 
cat on the mat that lacks a hair, there still seem to be at least 1001 cats on the mat.

Peter Geach's solution of the problem (cited by Wiggins, ibid., pp. 174-5) is phrased in terms of sortally relative identity: Let " $c_{0}$ " designate Tibbles, and " $c_{l}$ ", ..., " $c_{1000}$ " the relevant proper parts of Tibbles. Then, says Geach, $c_{0}$, $\mathrm{c}_{1}, \ldots, \mathrm{c}_{1000}$ are the same cat, but 1001 different masses of feline tissue; thus there is one cat on the mat, and at least 1001 masses of feline tissue.

But this cannot be right; I entirely agree with Wiggins regarding this point. For if $c_{i}$ is the same cat as $c_{k}$, then this is not an instance of an equivalence relation wider than absolute identity, as Geach believes, but implies: $c_{j}$ $=c_{k}$, and consequently-since $c_{k}$ is, among other things, a mass of feline tissue $-c_{j}$ must be (because of Leibniz's Law) the same mass of feline tissue $c_{k}$ is. Thus: if $c_{0}, \ldots, c_{1000}$ are one and the same cat, $c_{0}, \ldots, c_{1000}$ must also be one and the same mass of feline tissue. If one affirms the antecedent of this conditional (in agreement with common sense), then one has to affirm its consequent (in disagreement with common sense); and if one denies its consequent (in agreement with common sense), then one has to deny its antecedent (in disagreement with common sense).

Nevertheless, Geach is certainly on the right track. We merely need to put his intuition in terms of identity relative to sortal interpretation-and not in terms of sortally relative identity. Considered as masses of feline tissue, the entities $c_{0}, \ldots, c_{1000}$ are all different from each other. Considered as cats, however, the entitities $c_{0}, \ldots, c_{1000}$ are all identical to each other. And the entities $c_{0}, \ldots, c_{1000}$ can certainly be interpreted either as cats (or rather: as one and the same cat) or as masses of feline tissue (namely, 1001 different ones).

There is still one last hitch. How can $c_{j}$, considered as a cat, be identical with $c_{k}$, considered as a cat, in spite of the fact that $c_{j}$ and $c_{k}$ do not have, for $j$ $\neq \mathrm{k}$, quite the same spatial (three-dimensional) location at time $t$ when Tibbles is sitting on the mat? The answer is this: not only identity is relative to sortal interpretation, but also spatial location. As cats (but not as masses of feline tissue), $c_{\mathrm{j}}$ and $\mathrm{c}_{\mathrm{k}}$ do have the same spatial location at $t$ (for all $\mathrm{j}, \mathrm{k}$ in 0 , $\ldots, 1000$ ), namely, the spatial location that is at $t$ (when Tibbles is sitting on the mat, in that particular posture) essential for them as cats. Which spatial location is that? That's not so easy to say, but it is certainly a proper part of the largest spatial location that all $c_{i}(0 \leq \mathrm{i} \leq 1000)$ as masses of feline tissue have in common at $t$. 